\title{
Três conceitos biológicos/paleontológicos que seguem as diretrizes dos PCN do ensino médio para aplicação em aulas de Biologia
}

THREE PALEOBIOLOGICAL CONCEPTS TO APPLY IN ELEMENTARY (HIGH SCHOOL) BIOLOGY CLASSES

\author{
Carolina Zabini, Maria Antônia Michels de Souza \\ 1 Depto. Geol. Rec. Naturais, Inst. Geoc. Unicamp, Campinas, SP, Brasil. carolinaz@ige.unicamp.br \\ 2 Rua Dom Pedro I, 805, Centro Norte, Dois Vizinhos/PR. CEP 85660-000. lagunense@hotmail.com
}

ABSTRACT: The present paper aims to present three examples of paleobiological themes that can be applied at high school classrooms. It follows the suggestions of interdisciplinary content in Biology (Brazilian parameters in this study levels). The aim is to provide means to teachers study, use these concepts, and apply them in high school classes. These subjects are important in order to nurture students (for their professional lives), and also to broaden their abstract knowledge with the intention of acquiring a great cultural vision and to permit them to build their own worldview (educated citizens). Examples addresses the following content: ecological changes occurred at the Proterozoic Eon (from the biotic activity), evolving Science and deep time. Each of these concepts is divided in three parts: 1) contextualization and application, 2) details of the approach and 3) activity. At the contextualization and application part the theoretical and bibliographical support for the activity are indicated and discussed. The second part give the ways of approaching the subject in the classroom; also, the connection between different areas (outside Biology) and the necessary materials are numbered. At last, there is the explanation of the activity. These three concepts (past versus present environmental change, Science development and deep time) not only refer to Paleontology but also to the development of Science in general. They also encompass paleoenvironmental contexts and central questions on evolution of species and Earth itself, providing a a greater view on subjects that are commonly treated separately on school. Such examples should always be taught in an interdisciplinary manner, and if possible, in a conjunction of two or more teachers of differing areas.

\section{Introdução}

O presente texto objetiva expor três conceitos clássicos ligados às Ciências Biológicas e à Paleontologia na forma de aulas e exercícios práticos que possam ser aplicados em salas de aula de Biologia, para o Ensino Médio (EM). Pretende-se fornecer este material como uma forma de apoio para que os professores de Biologia (EM) apliquem as diretrizes fornecidas pelos Parâmetros Curriculares Nacionais (PCN) em sala de aula, abordando conceitos que normalmente não aparecem nos livros didáticos utilizados e cujas relações interdisciplinares são de construção complexa.

Como exemplos que inspiraram o desenvolvimento deste trabalho podem ser citados o "Livro Digital de Paleontologia: a Paleontologia na sala de aula" (Soares 2009) e o projeto "Experimentoteca do Ensino médio" (Scheil 2009, ver referências para consultar os sítios nos quais estes projetos estão disponibilizados). Ambos são projetos fundamentados na ideia de profusão do conhecimento Biológico e Paleontológico através da formação continuada do professor e no fornecimento e aplicação de exercícios práticos.

Conforme publicado por Moraes et al. (2007) e Faria et al. (2012) conceitos paleontológicos básicos raramente são citados no material didático utilizado por professores do EM, e quando o são não passam de simples citações sem contexto adequado. Conforme Schwanke e Silva (2004) a paleontologia é subutilizada na educação brasileira como um todo. Visando suprir, em parte, esta deficiência e, em conjunto com ações de formação continuada, pretende-se aqui ampliar o uso de conceitos paleontológicos, não somente os básicos, como já vem sendo efetuado por diversas ações em instituições pelo país (Soares 2009) mas também conteúdos mais complexos que podem ser inseridos no ensino de Biologia, e cujo cerne é também paleontológico.

De acordo com o PCNEM, no EM o professor deve aprofundar os conteúdos do ensino funda- 
mental (Biologia Física, Química e Matemática), e, com a maior maturidade dos alunos, deve propiciar o desenvolvimento de valores. O texto introdutório dos PCN trata ainda da interdisciplinaridade nos conteúdos e enfatiza a necessidade de serem compreendidos não somente conhecimentos práticos e contextualizados (para a vida profissional), mas também conhecimentos mais amplos e abstratos para que o aluno adquira uma visão cultural ampla e construa a sua visão de mundo (formação do cidadão). Não se pode deixar de lado também a questão da utilização do conhecimento prévio do aluno, que deve ser trabalhado e relevado na construção da aula e na transmissão/construção do conhecimento. Sobre a Biologia, em particular, o PCN fala:

"O aprendizado disciplinar em Biologia, cujo cenário, a biosfera, é um todo articulado, é inseparável das demais ciências. A própria compreensão do surgimento e da evolução da vida nas suas diversas formas de manifestação demanda uma compreensão das condições geológicas e ambientais reinantes no planeta primitivo. $\mathrm{O}$ entendimento dos ecossistemas atuais implica um conhecimento da intervenção humana, de caráter social e econômico, assim como dos ciclos de materiais e fluxos de energia”. (Brasil 1998, pág. 9)

E ainda:

"Um tema central para a construção de uma visão de mundo é a percepção da dinâmica complexidade da vida pelos alunos, a compreensão de que a vida é fruto de permanentes interações simultâneas entre muitos elementos, e de que as teorias em Biologia, como nas demais ciências, se constituem em modelos explicativos, construídos em determinados contextos sociais e culturais. Essa postura busca superar a visão a-histórica que muitos livros didáticos difundem, de que a vida se estabelece como uma articulação mecânica de partes, e como se para compreendê-la, bastasse memorizar a designação e a função dessas peças, num jogo de montar biológico". (Brasil 1998, pág. 15).

Quadro 1. Tópicos da Atividade 1 Etapa 1.

Principais tópicos a serem apontados pelo professor com a atividade 1, etapa 1

$>$ Uso da matemática na Biologia, como a aplicação da regra de três para a produção do tempo geológico em 24 hs;

> A compreensão de temas complexos, como o tempo profundo, pode ser realizada através de analogias, como a comparação de todo o tempo geológico e seus eventos dispostos em apenas 24 horas;

$>$ Reflexão sobre os principais eventos biológicos, listado na tabela 1, e sua sucessão.
Dessa forma, o objetivo dos exemplos é fornecer uma visão interdisciplinar de assuntos relacionados à Paleontologia e às Ciências em geral, conforme recomendado pelo PCNEM e que muito raramente é ofertado pelos livros sugeridos e utilizados aos/pelos professores deste nível de ensino.

\section{Exemplo 1}

Aqui as atividades com os alunos serão divididas em dois momentos: no primeiro o professor irá trabalhar a confecção de uma tabela do tempo profundo, comparada a um calendário de um dia (Etapa 1) e no segundo a compreensão de conceitos de evolução e de eventos terrestres importantes na diversificação das espécies por meio de uma atividade em sala de aula, destacando eventos responsáveis pela extinção e diversidade da vida primordial (Etapa 2). O quadro 1 mostra os principais tópicos a serem levantados pelo professor.

\section{Etapa 1}

\section{Elaboração de uma tabela do tempo profundo}

A tabela do tempo profundo (Fig. 1.) mostra de forma organizada os eventos geológicos e biológicos do planeta Terra; com o intuito de facilitar o processo de apropriação do conhecimento, mediado pelo professor, é recomendado que este solicite à classe a elaboração de uma tabela geológica ou do tempo profundo, formando no mínimo quatro grupos com cinco indivíduos cada. Cada grupo receberá uma tabela do tempo (Fig. 1) e ficará responsável por um intervalo de tempo (grupo 1: Pré-Cambriano, grupo 2: Paleozoico, grupo 3: Mesozoico e grupo 4: Cenozoico). É sugerido que o exercício seja trabalhado em sala de aula, a fim de permitir a consulta ao professor das eventuais dúvidas, criando o clima propício para a construção do conhecimento, facilitando a interação do aluno com o professor.

Embora o método usual na elaboração de uma tabela seja no papel cartolina, este pode ser 


\begin{tabular}{|c|c|c|c|c|c|}
\hline \multirow{2}{*}{ Éons } & \multirow{2}{*}{ Eras } & \multirow{2}{*}{ Períodos } & \multicolumn{2}{|c|}{ I níc i o } & \multirow{2}{*}{$\begin{array}{c}\text { Duração } \\
\text { (horas) }\end{array}$} \\
\hline & & & em anos & 24 Horas & \\
\hline \multirow{11}{*}{ Fanerozoico } & \multirow{2}{*}{ Cenozoico } & Quaternário & 1.800 .000 & 23:59:25 & 0:00:35 \\
\hline & & Terciário & 65.000 .000 & $23: 39: 12$ & $0: 20: 13$ \\
\hline & \multirow{3}{*}{ Mesozoico } & Cretáceo & 146.000 .000 & $23: 13: 17$ & $0: 25: 55$ \\
\hline & & Jurássico & 208.000 .000 & $22: 53: 26$ & $0: 19: 50$ \\
\hline & & Triássico & 245.000 .000 & $22: 41: 36$ & $0: 11: 50$ \\
\hline & \multirow{6}{*}{ Paleozoico } & Permiano & 286.000 .000 & 22:28:29 & 0:13:07 \\
\hline & & Carbonífero & 360.000 .000 & 22:04:48 & $0: 23: 41$ \\
\hline & & Devoniano & 410.000 .000 & $21: 48: 48$ & $0: 16: 00$ \\
\hline & & Siluriano & 440.000 .000 & $21: 39: 12$ & 0:09:36 \\
\hline & & Ordoviciano & 505.000 .000 & $21: 18: 24$ & $0: 20: 48$ \\
\hline & & Cambriano & 544.000 .000 & 21:05:55 & 0:12:29 \\
\hline \multicolumn{3}{|c|}{ Proterozoico } & 2.500 .000 .000 & 10:40:00 & 10:25:55 \\
\hline \multicolumn{3}{|c|}{ Arqueano } & 3.800 .000 .000 & $3: 44: 00$ & 6:56:00 \\
\hline \multicolumn{3}{|c|}{ Hadeano } & 4.500 .000 .000 & 0:00:00 & $3: 44: 00$ \\
\hline
\end{tabular}

Figura 1. Tabela do tempo profundo mostrando os principais eventos biológicos da história do planeta em escala de tempo real e em 24 hs. Modificado de Filho s/a.

construído na forma de maquete, incentivando a criatividade do educando.

Cabe ao professor destacar os principais fatos biológicos e/ou geológicos ocorridos ao longo do tempo. Além disso, caberá aos alunos descobrir a hora equivalente ao evento, num calendário em que 4,5 G.a. corresponderão a 24 hs. Aqui, um professor de matemática poderá acompanhar a atividade para auxiliar os alunos nos cálculos.

\section{Etapa 2}

\section{Contextualização e aplicação}

O exemplo a ser utilizado agora trata sobre o conceito de transformação ambiental, com a comparação entre o Hadeano/Proterozoico e a origem e diversificação da vida comparada ao clima mundial atual (Holoceno) e suas interferências relacionadas à ação antrópica.

Pouco se comenta durante os primeiros anos escolares (ensinos fundamental e médio) que a vida na Terra surgiu há muito tempo e que ela mesma provocou diversas mudanças ambientais que proporcionaram seu próprio desenvolvimento (Teoria de Gaia). Segundo Suguio \& Suzuki (2003) não se pode separar nem diferenciar a evolução biológica das mudanças paleoambientais, uma vez que tais mudanças agem como forças seletivas, determinantes para a ocorrência de eventos de extinção e de especiação (conceitos vistos em Ciências e Biologia) que impulsionam a evolução dos seres de maneira contínua no tempo.

No início da formação do planeta Terra (há cerca de 4,6 G.a. ${ }^{1}$ ) ele era muito quente e recebia uma quantidade muito grande de impactos de asteroides (a teoria mais aceita da formação da Terra implica em acreção de planetesimais). Pouco se sabe sobre o período de tempo entre sua origem e os 800 M.a. seguintes (que definem o Éon Hadeano, numa alusão ao Deus Hades, do inferno), pois grande parte das rochas desta época foram recicladas, uma vez que a crosta era mais quente e delgada, e havia o intenso bombardeio por asteroides (Anelli \& Simões 2011).

O próximo Éon, o Arqueano, teve uma duração de 1,3 G.a. (de 3,8 a 2,5 G.a.). Nele foram encontradas as primeiras evidências de vida $(3,5$ G.a.) de procariontes. Mas a vida possivelmente só surgiu porque a contínua e intensa queda de meteoritos parou e o planeta iniciou seu resfriamento, permitindo a precipitação de vapor d'água e a formação dos primeiros oceanos. O oxigênio era escasso e os procariontes surgiram no mar; a atmosfera primitiva ainda não os protegia contra os raios ultravioletas (raios UV), e a água do mar tinha este papel protetor (Suguio \& Suzuki 2003, Anelli \& Simões 2011).

1 G.a. - Giga ano ou Bilhões de anos atrás. 
A história da vida na Terra foi relatada por Duve (1997) e Margulis \& Sagan (2002) nas respectivas obras "Poeira Vital" e "O que é Vida". Nestas os referidos autores descreveram como a vida surgiu a partir da combinação de moléculas essenciais presentes no mar primitivo, compondo o que denominaram de sopa nutritiva que, em dado momento, foram encerradas por uma protomembrana propiciando um ambiente apropriado para a realização da auto-replicação, do que seria o RNA primitivo, que mais tarde derivaria no DNA. Assim, a protocélula do procarionte ancestral seria capaz de multiplicar-se e de passar as suas características hereditárias às próximas gerações.

O próximo passo evolutivo importante na trajetória da evolução da vida foi a origem da célula eucariótica, explicada pela teoria da Endossimbiose proposta por Lyn Margulis em 1981, que mostra a ancestralidade dos eucariontes a partir de seres procarióticos que se associaram em simbiose durante o Éon Proterozóico. Foi nesse mar primitivo que as cianobactérias evoluíram e, através da fotossíntese, iniciaram uma grande produção de oxigênio, que se acumulou na atmosfera. Grandes depósitos de ferro espalhados pelo mundo moderno (como as rochas que formam hoje o Quadrilátero Ferrífero, em Minas Gerais) são resultado deste processo. A formação dessa rocha com camadas ricas em ferro ocorreu da interação entre o $\mathrm{O}_{2}$ produzido pelas bactérias e o $\mathrm{Fe}^{3+}$ disponível no ambiente. Neste tempo, o oxigênio produzido reagia imediatamente com compostos químicos reduzidos disponíveis no meio (gases vulcânicos, minerais e compostos químicos dissolvidos na hidrosfera). As rochas formadas neste processo são chamadas formações ferríferas bandadas (Fairchild 2003, Anelli \& Simões 2011). Após toda a oxidação destes compostos disponíveis é que houve a acumulação gradativa de oxigênio na atmosfera. Este oxigênio disponível e abundante (cerca de 1\% da atmosfera atual) causou uma grande crise ambiental, consequente da condição elevada de toxicidade, formando produtos reativos no interior das células, como radicais hidroxílicos, íons de superóxidos e peróxido de hidrogênio que danificam o DNA e as bicamadas lipídicas (Duve 1997). Todavia, a crise selecionou organismos que toleravam a presença do $\mathrm{O}_{2}$, e, que mais tarde derivaram a condição de respiração aeróbia. Portanto, é possível que neste momento do tempo geológico uma linhagem ancestral de "bactérias extremófilas" derivaria para uma nova forma de bactéria, as cianobactérias, grupo que originaria as algas cianofíceas capazes de utilizar a água como fonte de hidrogênio, liberando o oxigênio em abundância na atmosfera terrestre (Margulis \& Sagan 2002). Este evento fez parte do cenário propício ao aparecimento da multicelularidade, seguida da complexidade dos organismos eucariotos (primeiros registros em 1,8 G.a., no Éon Proterozoico) e da extinção de muitas linhagens de bactérias que não toleravam oxigênio. A presença e a acumulação gradativa de oxigênio exerceram uma pressão seletiva nos organismos viventes neste tempo (Fairchild 2003, Suguio \& Suzuki 2003), moldando a evolução da vida dali em diante (Tyson \& Goldsmith 2015).

Ao final do Éon Proterozoico acredita-se que ocorreu um grande evento de glaciação global, em que praticamente o planeta todo sofreu congelamento (Terra "bola-de-neve"). Acredita-se que a vida tenha resistido próxima a vulcões, onde a água mantinha-se descongelada (Anelli \& Simões 2011).

Foi por meio de fusões simbiônticas citadas anteriormente, que algumas formas bacterianas evoluíram para os protistas (organismos unicelulares), entre os quais se incluem as algas unicelulares, as amebas, os ciliados, entre outros (Margulis \& Sagan 2002). Da mesma forma a multicelularidade entra em cena com a evolução da associação de certas células eucarióticas ancestrais (de alguns protistas), que permitiu a diversificação de várias linhagens de animais, fungos e plantas (Hickman et al. 2013). No caso dos animais (Metazoa), por exemplo, no registro fóssil tem-se mostrado a diversificação da maioria dos filos entre 570 e 600 milhões de anos na transição do Pré-Cambriano (Proterozoico) para o Cambriano (Fanerozoico). É possível que os metazoários tenham um ancestral protista, formando um grupo monofilético.

A teoria que melhor explica a origem colonial dos Metazoa foi proposta por Ernst Haeckel em 1874, que apregoa que um protista monoflagelado colonial teria dado origem a um ancestral metazoário planulóide, muito similar às larvas plânula dos cnidários (águas vivas, corais e anêmonas). A presença de células monoflageladas ou monociliadas nas paredes corpóreas de animais basais como Porifera e Cnidaria (Brusca \& Brusca 2007) é um dado importante que sustenta esta hipótese.

O processo de diversificação da vida continuou intensamente durante todo o Éon Fanerozóico (últimos 600 M.a.) (e permanece até hoje); porém não é a intenção deste trabalho detalhar estes eventos subsequentes. O objetivo agora é comparar 
os processos ocorridos no Proterozoico relatados anteriormente (formação da atmosfera, respiração e fotossíntese, surgimento de grupos e extinção de outros) com os processos recentes de mudanças climáticas e suas consequências. Isso significa comparar alguns bilhões de anos do Proterozoico com os últimos 100 anos de história e ação antrópica, conforme os tópicos expostos no quadro 2.

Cabe ao professor procurar material para instigar a questão sobre os atuais processos que estão sendo aceleradores da "destruição" (modificação?) do meio ambiente, da extinção de outras espécies e o próprio aquecimento global tão discutido na mídia.

\section{Detalhamento da abordagem}

Caso a atividade do tempo profundo (exemplo 1, etapa 1) já tenha sido desenvolvida com os alunos num momento anterior, pode-se relembrar e discutir o tempo envolvido para o surgimento da atmosfera, do aparecimento dos primeiros procariontes e dos eucariontes) em comparação com as poucas centenas de anos envolvidos nas mudanças climáticas.

As informações fornecidas anteriormente são importantes na problematização durante a atividade em classe, onde o professor introduzirá o tema a ser trabalhado e o que ele espera que os alunos concluam após a atividade, chegando a ponto de discernirem sobre os ciclos paleoclimáticos do planeta Terra, trazendo o conhecimento para a atualidade com relação ao efeito estufa e as mudanças climáticas ocorrentes em curto espaço de tempo. Para esta atividade a construção da tabela de tempo geológico é essencial; além disso, o acompanhamento de um professor de química poderá auxiliar os alunos na compreensão do metabolismo dos primeiros organismos (diferenciar a fotossíntese da respiração, quimicamente; explicar como se deu a oxidação das imensas quantidades de ferro disponíveis no ambiente, a formação das formações ferríferas bandadas e a própria formação da atmosfera primitiva).

A atividade em si, detalhada a seguir, será referente aos processos envolvidos na crise que foi originada com o evento de grande oxigenação da atmosfera. Cabe ao professor, após a atividade aqui detalhada, fazer a ligação do tema com as mudanças climáticas atuais. O quadro 2 mostra os principais tópicos a serem abordados.

\section{Material utilizado}

- Bexigas, cerca de 50 unidades de pelo menos 5 cores diferentes onde cada uma representará um gás diferente (metano $\mathrm{CH}_{4}$, amônia $\mathrm{NH}_{3}$, monóxido de carbono $\mathrm{CO}$, e sulfetos de hidrogênio $\mathrm{H}_{2} \mathrm{~S}$ ); por sugestão a cor azul deve representar $\mathrm{o}_{2}$;

- 1 garrafa pet com sua parte superior recortada;

- Se disponível, uma amostra de rocha de Itabirito (formação ferrífera bandada) para mostrar aos alunos;

- Calendário geológico produzido na atividade 1 , etapa 1 ;

- Papel pardo cortado em tiras finas;

- Placas de papel cartão

\section{Descrição da Atividade}

O objetivo desta atividade é permitir que o aluno construa o conhecimento, de forma lúdica, acerca dos gases presentes na atmosfera primitiva e na atual, permitindo a associação dos primeiros seres vivos com o meio ambiente, e os impactos

Quadro 2. Tópicos da Atividade 1 Etapa 2.

Principais tópicos a serem apontados pelo professor com a atividade 1, etapa 2

$>$ O tempo envolvido no processo de formação da atmosfera;

> O tempo envolvido nos processos atuais de mudanças climáticas;

$>$ A forma como a vida moldou a composição da atmosfera;

> A pressão seletiva atuante nos organismos durante a formação da atmosfera oxigenada;

> Comparar a quantidade de organismos envolvidos em ambos processos (diversidade primitiva, composta basicamente por unicelulares x diversidade atual de espécies);

Comparar a influência dos eventos para a evolução da vida. 
positivos e negativos para a diversidade de espécies e a extinção como consequência das alterações ambientais. Além disso, deve-se discutir que a evolução da vida está ligada à evolução do planeta. Um esquema geral mostrando a dinâmica da atividade está representado na Fig. 2.

Encher as bexigas com os alunos, antes de iniciar a aula; escrever em cada bexiga o símbolo de um gás tóxico presente na atmosfera primitiva (metano $\mathrm{CH}_{4}$, amônia $\mathrm{NH}_{3}$, monóxido de carbono $\mathrm{CO}$, e sulfetos de hidrogênio $\mathrm{H}_{2} \mathrm{~S}$ ). Deixar um número pequeno de bexigas da cor azul $\left(\mathrm{O}_{2}\right)$ em meio às outras bexigas, todas penduradas por um barbante em um anteparo fixo, representando os gases da atmosfera. Reservar um número considerável de bexigas azuis $\left(\mathrm{O}_{2}\right)$ para serem utilizadas em outro momento da atividade.

A seguir dividir a turma em dois grupos de número igual ou aproximado de alunos. Onde um grupo representará os procariontes e o outro os eucariontes. Para facilitar a diferenciação dos dois grupos de alunos, entregue placas sinalizadoras feitas de papel cartão com duas cores diferentes escritos em cada um a letra $\mathrm{P}$ para os procariontes e E para os eucariontes, por exemplo. Porém no início da atividade somente os procariontes serão ativos. Entre os procariontes determinar grupos de alunos para representar diferentes tipos de bactérias (fornecer cartões informando que organismo o grupo representa, se é ou não anaeróbio e se é resistente ao oxigênio); neste momento é possível abordar os conceitos sobre as estruturas das células procariontes. O professor pode utilizar modelos de células procarióticas, diferenciando as bactérias heterotróficas das autotróficas, chamando a atenção para os processos metabólicos da respiração celular, diferenciando aquelas que exclusivamente utilizam os gases de enxofre das que apresentam a pré-disposição (oriunda de mutações) na resistência ao oxigênio como subproduto da respiração.

Em adição, o professor pode introduzir a teoria de Lynn Margulis da endossimbiose, que afirma que as variações herdadas se devem à interação entre os organismos em longo prazo, como ocorreu na origem das primeiras células nucleadas a partir da fusão de bactérias primitivas há bilhões de anos.

Após o surgimento dos organismos fotossintetizantes, há a adição de $\mathrm{O}_{2}$ na atmosfera, que, no entanto, oxida o ferro férrico disponível no ambiente. O evento da grande oxigenação atmosférica funcionou como uma pressão seletiva importante na extinção por oxidação, a qual resultaria no

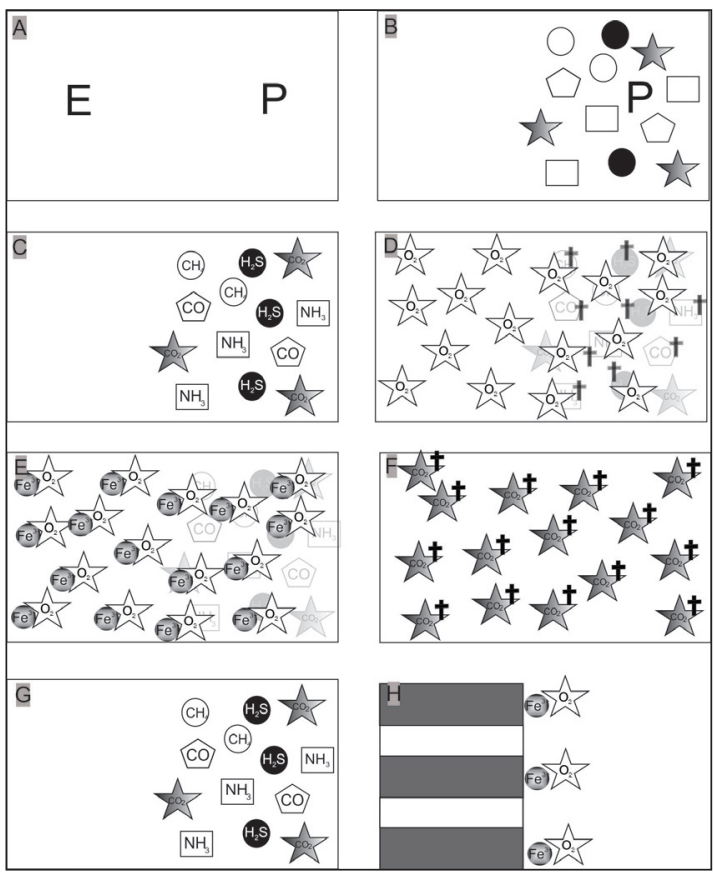

Figura 2. Esquemas mostrando a dinâmica da atividade em sala de aula. A) separar alunos que representam $\mathrm{E}$ (eucariontes) de $\mathrm{P}$ (procariontes); os alunos representantes de cada grupo se dirigem a lados opostos da sala; B e C) dentre os alunos que representam os procariontes, definir seus tipos metabólicos (por isso mostra-se o surgimento de cianobactérias utilizando $\mathrm{CO}_{2}$, e consequentemente produzindo $\left.\mathrm{O}_{2}(\mathrm{D}) ; \mathrm{D}\right)$ representa a morte das outras comunidades de procariontes (cruzes indicam este processo); E) todo o $\mathrm{O}_{2}$ produzido em $\mathrm{D}$ é oxidado. Esta oxidação gera uma camada de sedimentos rico em ferro (ver $\mathrm{H})$; F) a superpopulação de cianobactérias provoca o esgotamento dos recursos do ambiente e grande parte delas é eliminada temporariamente. G) A eliminação das cianobactérias e a oxidação do $\mathrm{Fe}^{3+}$ produzido por elas permite o retorno das outras bactérias ao ambiente. $\mathrm{O}$ ciclo se reinicia (voltar a D). H) representa a estruturação (formações ferríferas bandadas) que irá surgir na garrafa pet, com a colocação das camadas de bexigas. Ao final deste processo de aumento da quantidade de $\mathrm{O}_{2}$ na atmosfera e sua estabilização, algumas formas procariontes serão extintas e outras sobreviverão em ambientes marginais.

rompimento da membrana celular e na destruição das proteínas de muitos microrganismos (primeira extinção do Proterozoico cerca de 1,8 bilhões de anos atrás), criando nichos ecológicos vagos, que permitiu que outros seres com resistência a este gás, ocupassem estes espaços.

Para representar a oxidação do ferro, as bexigas de oxigênio podem ser estouradas e seus restos inseridos na garrafa pet cortada (que é construído aqui para representar uma porção do que seria o 
fundo dos mares daquela época). A seguir os organismos não tolerantes ao oxigênio acabam morrendo pela sua elevada concentração, o que é registrado como rochas com camadas com pouco ou nenhum ferro. Este processo pode ser representado na garrafa por uma camada de folhas de papel cortada.

Por muitas vezes o processo de oxidação do ferro e morte dos organismos se repete, e será possível observar na garrafa a estruturação de uma formação ferrífera bandada. Da mesma forma, os alunos poderão compreender as etapas de desenvolvimento dos organismos neste estágio de vida primordial.

Com o tempo, todo o ferro disponível será oxidado e os organismos que sobreviveram ao $\mathrm{O}_{2}$ irão utilizá-lo em sua respiração em substituição ao do ancestral. A partir daí há uma acumulação gradativa de $\mathrm{O}_{2}$ na atmosfera, momento do surgimento de organismos mais complexos (segunda parte da turma pode representar organismos eucariontes - relembrar os conceitos deste tipo de célula), ao mesmo tempo em que mais bexigas de oxigênio começam a ser liberadas na sala.

Cabe ao professor perguntar aos alunos o tempo envolvido neste processo, a complexidade e a forma como a vida moldou a atmosfera, que por sua vez exerceu uma pressão seletiva nos organismos e só aqueles que estavam aptos às condições desse novo ambiente conseguiram sobreviver. Cabe também a comparação do tempo envolvido neste processo com o tempo de existência do homem na Terra, e do qual se comenta tanto atualmente que está modificando o seu meio ambiente em uma escala muito rápida, o contrário do que ocorreu nos eventos ora comentados, não permitindo que os organismos em situações semelhantes de estresse ambiental do mundo moderno (como o efeito estufa) tenham um tempo de resiliência muito curto, implicando no insucesso de uma "estabilidade" ecológica, quando as populações conseguem manter um fluxo gênico adequado, evitando a extinção.

Com este exercício não se pretende criar a falsa ilusão de que o homem não está destruindo sua própria casa de modo muito rápido, mas sim objetiva a reflexão dos estudantes em relação às diversas mudanças já ocorridas na Terra ("ativadas" tanto pela evolução geológica quando pela biológica); é interessante destacar que a pressão evolutiva que nós estamos criando poderá ser uma barreira para o desenvolvimento de nossa própria espécie no futuro. Conforme sugere Suguio \& Suzuki (2003) mesmo que o ser humano seja muito frá- gil em comparação com o planeta e sua evolução, ele é sim responsável por grande prejuízo a outras espécies, e que ele tem danificado o seu ambiente de forma irrecuperável na escala humana. Dito isso, "não seria então uma obrigação nossa, de utilizar o conhecimento que se tem sobre a história da Terra, para preservar o planeta e a vida que ele contém?" (Suguio \& Suzuki 2003).

\section{Exemplo 2}

\section{Contextualização e aplicação}

O segundo conteúdo a ser abordado neste capítulo tem como objetivo discutir a evolução do conhecimento científico, com um exemplo de prática comum no século XIX e que atualmente é considerado preconceituoso e que caiu em desuso. A discussão deste conteúdo com os alunos objetiva fazê-los refletir sobre os seguintes aspectos: a ciência não é meramente uma aglomeração de dados científicos, é preciso refletir sobre os dados obtidos cientificamente para que não ocorram interpretações errôneas. A ciência está inserida num contexto social, e como os cientistas são pessoas - também dentro deste contexto - muitas das conclusões científicas são fortemente influenciadas por ele, positiva ou negativamente.

A craniometria ou craniologia era uma prática muito comum na ciência do século XIX e início do século XX. Sua definição atual a restringe em uma ciência que mede os ossos do crânio; porém, anteriormente, essas medições eram utilizadas na definição de inteligência humana e para a categorização de raças.

Os textos de Gould (2004), intitulados: "Chapéus largos e mantes estreitas" e "Os cérebros das mulheres" do livro "O polegar do panda" são a base da presente discussão. No primeiro, há o relato da medição do crânio de Georges Cuvier (naturalista francês considerado o pai da Paleontologia de Vertebrados, idealista do catastrofismo, morto em 1832). Após a morte de Cuvier, Broca, um dos grandes craniologistas da época, lutava para difundir seu ideal de que o tamanho do cérebro deveria ser utilizado para medir o valor relativo dos povos. Cuvier era muito conhecido por possuir uma "cabeça maciça" sic e dois dias após a sua morte, ocorrida no dia 13 de maio, seus colegas, resolveram abrir o seu crânio em nome da ciência. Nenhuma estrutura diferenciada foi reconhecida no cérebro de Cuvier, porém 
ele pesava $1.830 \mathrm{~g}$, quase $400 \mathrm{~g}$ a mais que a média de cérebros já pesados até então. Assim o cérebro de Cuvier foi considerado "a primeira prova direta de que o brilhantismo e o tamanho do cérebro caminham lado a lado".

Porém, o rival de Broca, Gratiolet, ao rever os documentos relativos ao procedimento de autópsia do crânio da Cuvier percebeu que nada havia sido anotado (nem o peso, nem as medidas) e que nem o cérebro, nem o crânio dele haviam sido preservados. Dessa forma ele pode questionar as informações fornecidas por Broca, e partiu para uma análise que pudesse questionar aqueles dados. Pôs-se então a estudar o chapéu de Cuvier, numa forma de obter informações sobre o tamanho de sua cabeça. Gratiolet conseguiu recuperar as medidas tomadas pelo chapeleiro de Cuvier e obteve os seguintes números: o chapéu media $21,8 \mathrm{~cm}$ de altura e 18 $\mathrm{cm}$ de largura, sendo que a altura estava um pouco acima dos 21,5 cm de altura de maior tamanho de chapéus. Portanto, Gratiolet afirmou que a cabeça de Cuvier não estava fora da média em tamanho ("embora grande, não era excepcional ou única").

Os adeptos de Broca preferiram ignorar os dados de Gratiolet uma vez que eram advindos de uma peça de vestuário, e continuaram a apoiar as ideias de Broca.

Alguns anos depois, em 1883, outro cientista descobriu os dados relativos à autópsia e conseguiu provar que o cérebro do grande homem era realmente grande e afirmou "a circunferência maior do crânio só pode ser igualada por $6 \%$ dos cientistas e homens de letras (medidos em vida com cabelo) e por $0 \%$ dos criados domésticos" sic.

Como explicado por Gould, é necessário que reflitamos a respeito do contexto social e o próprio momento histórico vivido por estes craniologistas. A medição dos cérebros tinha como objetivo explicar os motivos do sucesso de alguns grupos humanos e do fracasso de outros. Com este objetivo explícito, os números e a categorização de tipos (homens $\mathrm{x}$ mulheres, brancos x negros, homens de gênio $\mathrm{x}$ pessoas comuns) eram a forma que eles encontraram para justificar suas análises e conclusões. A craniologia de pessoas eminentes continuou a ser realizada e já em 1907, com o aumento do número de medições, os dados tornavam-se cada vez mais ambíguos. No entanto, E.A. Spitzka, eminente profissional do ramo, mantinha-se impávido em relação às ambiguidades e expôs seus dados de forma a se adaptarem a um preconceito: dispôs, nesta ordem: o cérebro de um grande homem, o de uma bosquí- mane africana e o de um gorila e concluiu: "O salto de um Cuvier ou de um Tackeray para um zulu ou um bosquímane não é maior que o do último para um gorila ou um orangotango" sic.

Atualmente, e de forma geral, não se utiliza da ciência para a diferenciação racial ou a quantificação da inteligência, mas ainda é muito difundido entre as pessoas a idealização de que "quanto mais (ou maior) melhor". Até onde se sabe o tamanho ou a forma do cérebro não reflete mudanças na inteligência, sendo a sua estrutura física a responsável direta por isso.

\section{Detalhamento da abordagem}

Estes textos de Gould sugerem uma mudança na visão de mundo em relação à craniologia, antes pensada como uma maneira de categorizar diferenças entre gêneros e raças humanas. Dessa forma, com este exemplo pode-se mostrar aos estudantes como a ciência progride, e de que forma ela é influenciada por seu contexto social e histórico. Além disso é possível discutir que a ciência não é meramente um conjunto de dados que implicam em uma verdade, mas a forma como estes dados são tratados também deve ser a mais parcimoniosa e isenta possível.

Para a abordagem deste conteúdo, além dos textos de Gould (2004) citados na contextualização (pág. 110), o filme intitulado "O elo perdido" (título em inglês: "Man to man") do diretor Régis Wargnier, é fortemente indicado, ficando, no entanto, a cargo do professor a disponibilização de tempo para esta atividade. $\mathrm{O}$ acompanhamento de um professor de matemática poderá auxiliar na abordagem dos dados numéricos, o professor de história pode auxiliar na contextualização histórica e um professor de filosofia na abordagem relativa à origem das ciências. O quadro 3 mostra os principais tópicos a serem levantados.

\section{Material utilizado}

Figuras de crânios de pessoas de raça e gêneros diferentes (acessível em bases de dados 3D de alguns museus, como o Smithsonian, sites de busca da internet), tabela com dados de índices cefálicos;

- Tabela com dados craniológicos de diferentes pessoas (tab. 1). Sugere-se também a coleta de dados dos próprios alunos; para obter o índice cefálico as regiões a serem medidas estão expostas na Fig. 3).

- Filme "O elo perdido", descrito no 4. 
Tabela 1 Medidas de índices cefálicos fictícios, baseados no trabalho de Pereira et al (2008).

\begin{tabular}{c|c|c|c|c}
\hline & \multicolumn{2}{|c|}{ Homens } & \multicolumn{2}{c}{ Mulheres } \\
\hline Idades & $\begin{array}{c}\text { Índice } \\
\text { cefálico }\end{array}$ & $\mathrm{n}$ & $\begin{array}{c}\text { Índice } \\
\text { cefálico }\end{array}$ & $\mathrm{n}$ \\
\hline 10-11 anos & 83,7 & 19 & 70,8 & 18 \\
\hline $12-13$ anos & 82,7 & 20 & 74,4 & 17 \\
\hline $14-15$ anos & 90,3 & 17 & 77,7 & 20 \\
\hline $16-17$ anos & 83,2 & 15 & 75,5 & 10 \\
\hline $18-19$ anos & 91,0 & 10 & 73,9 & 15 \\
\hline
\end{tabular}

\section{Atividade}

Fornecer aos alunos figuras de cérebros de pessoas de raça e gêneros diferentes e introduzir os princípios da craniologia (falar que se trata sobre medições dos ossos do crânio) e os dados da tabela 1. Realizar medições com os próprios alunos e montar uma tabela da turma.

Primeiro destacar os valores numéricos diferentes entre homens e mulheres, ou brancos e negros, por exemplo, de forma a incitar aos alunos a pensar que existem diferenças entre tais categorias. Após essa discussão inicial e a resposta dos alunos, informar que as diferenças ocorrem mais por variação do tamanho do corpo, e que na média, todos são semelhantes.

Contar a história da medição do cérebro de Cuvier e explicar, ao final, que os dados estavam sendo fornecidos de forma tendenciosa. Quando um grande número deles já havia sido medido estes números indicavam uma normalidade de dados (aqui o professor de matemática poderá também participar da aula).

Quadro 3. Tópicos da Atividade 2

Principais tópicos a serem apontados pelo professor com a atividade 1, etapa 2

> Discutir sobre a influência da sociedade na ciência e nos cientistas;

> Mostrar como valores númericos podem ser interpretados de forma errônea, como no caso dos valores do tamanho dos crânios;

Dalar sobre as diferenças morfológicas entre negros e caucasianos, por exemplo, explicando que tais diferenças não separam espécies ou mesmo raças.

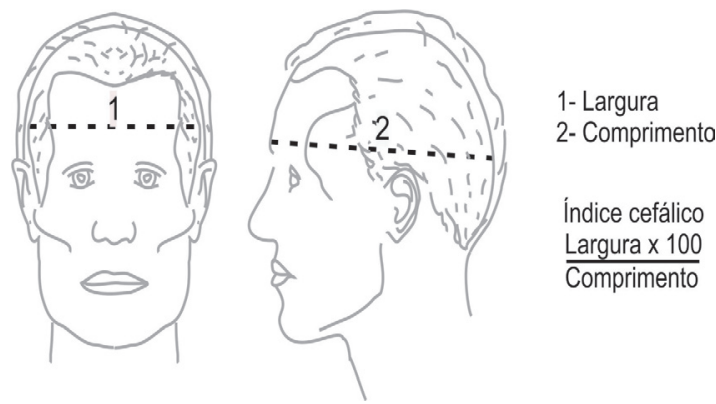

Figura 3. Imagem das medidas a serem obtidas para o cálculo do índice cefálico. De acordo com a enciclopédia britânica este índice se refere à razão entre a largura (multiplicado por 100) pelo comprimento do crânio. Índices $<75=$ crânio longo e estreito de visto de cima; termo usado para se referir a este tipo de crânio é dolicocefálico. Índices entre 75 e 80 = crânio quase oval; referido como mesaticefálico. Índices > 80 = largo e curto; referido como braquicefálico.

Finalizar mostrando aos alunos que a ciência também é influenciada por seu contexto social, e que está sempre mudando, e que atualmente a craniologia não é mais utilizada com objetivo de categorização de raças e gêneros.

Caso o filme possa ser exibido aos alunos, ele também faz alusão à quão cruel essas medidas craniológicas eram, pois no filme os bosquímanes são interpretados como uma raça inferior, o "elo perdido" entre homens e macacos. Porém, um dos cientistas envolvido no estudo começa a perceber o quão humanos, inteligentes e semelhantes a ele próprio os bosquímanes são, mostrando o quão pouco efetiva eram as medidas craniológicas.

Quadro 4. Ficha técnica do filme "O elo perdido"

\section{Ficha técnica do filme sugerido}

Título: Man to man (O Elo perdido)

Gênero: Drama

Direção: Régis Wargnier

Roteiro: Fred Fougea, Michel Fessler, Régis

Wargnier, William Boyd

Elenco: Cécile Bayiha, Flora

Montgomery, Hugh Bonneville, Iain

Glen, Joseph Fiennes, Kristin Scott Thomas

Produção: Farid Lahouassa

Fotografia: Laurent Dailland

Trilha Sonora: Patrick Doyle

Duração: 122 min. 


\section{Exemplo 3}

\section{Contextualização e aplicação}

O terceiro e último conteúdo a ser abordado é baseado no texto de Stephen J. Gould intitulado "O tempo de vida que nos foi concedido", publicado como um capítulo do livro (Gould 2004). Este texto aborda a questão do tempo profundo, considerada pela maioria dos autores da área como um ponto crucial para o entendimento da paleontologia. A ideia central do texto será repassada abaixo, mas sugere-se fortemente sua leitura completa para a aplicação dos conceitos envolvidos nesta aula.

Considerada uma ciência histórica, a paleontologia envolve uma vastidão de tempo que não é facilmente compreendida por nós humanos, acostumados que somos com a escala de nossas vidas, com a concepção de duração "longa" sendo aquele de um século. Diversos são os exemplos na literatura especializada que tentam promover a melhor comparação, ou analogia entre a vastidão do tempo e a escala de tempo de horas, dias, meses e anos as quais estamos acostumados. A mais comumente utilizada é aquela da inserção da escala do tempo geológico num calendário de um ano (Soares 2009, Teixeira et al. 2009). Outro exemplo encontrado na literatura é o do abismo do tempo (Holz \& Ros 2000) que diz que se alguém caísse num abismo de tamanho comparável em altura à vastidão do tempo geológico, essa pessoa morreria de fome e de sede muito antes do impacto com o chão. Alguns exercícios muito úteis também propõem a utilização de uma escala comum a todos, como por exemplo, utilizar-se da parede da sala de aula, para que se desenhe os principais eventos biológicos e geológicos ocorridos na evolução da Terra, para que se visualize a distribuição destes eventos e se perceba quão longa é essa história, e quão pequena é a participação do homem nela.

Gould (2004) inicia seu texto informando ao leitor alguns fatos biológicos em relação a diferentes espécies de mamíferos, explicitando as suas semelhanças e diferenças em relação ao tamanho dos seus corpos. Para a maioria dos mamíferos é observado que os menores vivem menos que aqueles de corpo maior. Isso porquê nos animais menores os pequenos corações devem bombear sangue mais rapidamente do que aqueles de animais maiores. Os pequenos mamíferos possuem elevadas taxas metabólicas e portanto aumentam o consumo de oxigênio e produzem mais calor, de maneira a compensar a perda de energia na forma de calor com maior facilidade para o ambiente do que os mamíferos maiores. Sendo assim, pelo tipo de metabolismo acelerado produzem mais toxinas, que causam o envelhecimento e a morte celular, como por exemplo, os radicais livres (Schmidt-Nielsen 1996; Hill et al. 2012).

Cabe aqui acrescentar que cachorros pequenos tendem a viver mais que cachorros de porte grande (ao contrário do que se afirmou no parágrafo anterior). Pesquisas recentes de Choi (2013) e Galis et al. (2007) mostraram que a seleção artificial realizada pelo ser humano propiciou maior longevidade para as raças de cães menores, e o contrário para as de maior tamanho, que em consequência do maior tamanho e da massa corpórea, adquiriram a predisposição ao desenvolvimento de problemas de saúde, que diminuem a longevidade.

Gould (2004) fornece algumas explanações sobre as diferenças no metabolismo de vários mamíferos e inicia a discussão que este metabolismo distinto deve ser uma forma de se perceber o tempo diferencialmente. Nós humanos temos sempre o hábito de fazermos comparações com aquilo que nos é comum. A escala de tempo humano é, para nós, suficientemente longa para podermos ter uma "boa e longa" - história de - vida. Assim, para um mamífero menor, como um rato, viver "somente" dois anos não deve ser percebido como pouco tempo, uma vez que o metabolismo dele é mais rápido. Dessa forma o autor segue adiante citando o exemplo das baleias que conseguem cantar por mais de 30 minutos, e repetir as canções de forma exatamente igual por uma centena de vezes - fato só percebido (por nós humanos) por estudos realizados com as gravações desses sons; não seríamos capazes de perceber que tais complexos ruídos poderiam ser repetidos de maneira idêntica por um período de tempo (neste caso) tão "longo" quanto 30 minutos.

Após a discussão dos diversos exemplos entre metabolismo de animais de diferentes tamanhos, Gould (2004) conclui que "medidos pelos relógios internos dos seus corações ou pelo ritmo da sua respiração, todos os mamíferos vivem o mesmo tempo". E finaliza com um exemplo, central a presente discussão da percepção do tempo e de sua vastidão; baseado num texto de Robert Chambers (1844), Gould (2004) compara a nossa percepção da história geológica da Terra e da evolução da vida à percepção de um inseto que, em sua fase adulta, 
vive somente um dia, como uma efeméride (Fig. 4), observando a metamorfose de um girino numa rã. Segue transcrito o texto de Chambers:

"Suponham que uma efeméride, pairando sobre um lago durante o seu único dia de vida de abril, fosse capaz de observar o bando de rãs nas águas abaixo. $\mathrm{Na}$ sua idosa tarde, não tendo visto qualquer mudança nas rãs durante um tempo tão longo, estaria pouco qualificada para conceber que as brânquias externas (guelras) dessas criaturas desapareceriam e seriam substituídas por pulmões internos, que pés se desenvolveriam, que a cauda seria eliminada e o animal se tornaria então um cidadão da terra" (Gould 2004, pág. 276).

"A consciência humana não surgiu senão no último minuto antes da meia-noite do relógio geológico. No entanto, nós, as efemérides, tentamos submeter o mundo ancestral aos nossos propósitos, ignorantes talvez das mensagens enterradas em sua longa história. Tenhamos esperança de estarmos ainda no início da manhã do nosso dia de abril" (Gould 2004, pág. 276).

\section{Detalhamento da abordagem}

Esta atividade deve ser desenvolvida em duas etapas, que podem, de acordo com a disponibilidade do professor, ser dividido em duas aulas. O quadro 5 mostra os principais tópicos a serem abordados.

\section{Etapa 1}

Sugere-se iniciar a abordagem informando aos alunos que a questão central da aula é sobre a relatividade do tempo, e que para se compreender a história geológica da Terra e a Evolução da vida deve se ter a noção do tempo profundo.

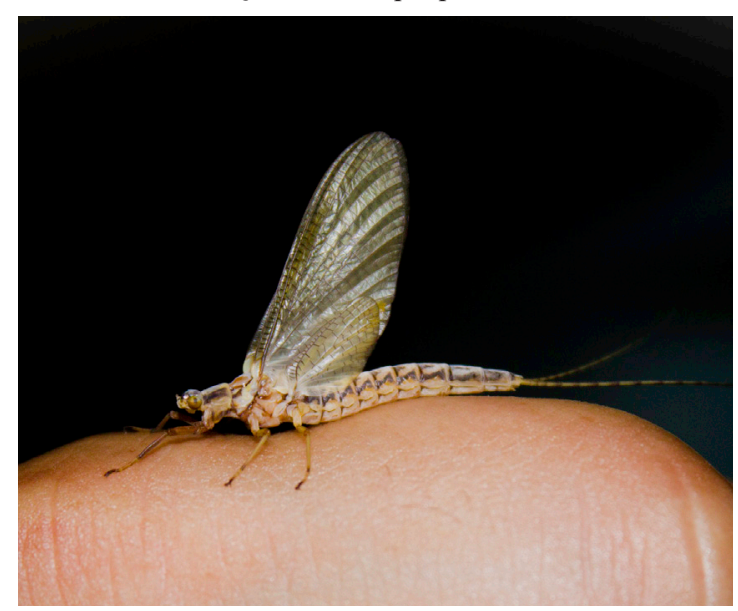

Figura 4. Exemplar adulto de efemérida.
Quadro 5. Tópicos da Atividade 3

Principais tópicos a serem apontados pelo professor com a atividade 3

$>$ Levantar os principais eventos biológicos ocorridos na história da vida e suas datas, dentro de um calendário de um ano;

$>$ Discutir sobre o conceito de tempo profundo e suas relações com a vida na Terra;

$>$ Abordar a questão da percepção do tempo para diferentes espécies.

\section{Material a ser utilizado}

As instruções para o desenvolvimento desta atividade podem ser encontradas no livro digital de paleontologia, capítulo sobre tempo geológico, atividade número 8 .

\section{Atividade}

Desenvolver a atividade do tempo geológico em um calendário de um ano. Caso os alunos tenham tempo, deixá-los resolver; caso contrário, expor no quadro o calendário com os principais eventos, e destacá-los em relação aos dias e meses do calendário, de forma que o aluno consiga visualizar a distribuição destes e o seu significado.

Com esta atividade resolvida, ou explanada em aula, os alunos deverão ter a dimensão do tempo envolvido na história da Terra e do desenvolvimento da vida; além disso serão capazes de perceber que quase não se é possível notar, nesta escala, a aparição da humanidade.

\section{Etapa 2}

Com base no texto de Gould podem ser exploradas diversas atividades com os alunos em sala, utilizando-se seu conhecimento de mundo e diferentes conteúdos biológicos, conforme sugerido a seguir:

\section{Material a ser utilizado}

- Gráfico 1 curva "rato-baleia";

- CD com sons de baleias ou na página do youtube https://www.youtube.com/ watch?v $=q U$ qs46B2vho;

- Imagens ou material biológico (caso disponível) do desenvolvimento de uma efeméride ou de uma borboleta; 
- Imagens ou material biológico (caso disponível) da metamorfose de uma rã;

- Calendário do tempo produzido na etapa anterior.

\section{Atividade}

Iniciar a etapa fornecendo exemplos de como nós humanos estamos acostumados a pensar em nossa escala de tempo e naquilo que vivemos no presente. Perguntar aos alunos se eles já pararam alguma vez para refletir sobre a infância dos seus avós. Neste caso, apontar que, assim como nossos pais e avós, todos tivemos infância, apesar de não refletirmos sobre isso com frequência, uma vez que não os conhecíamos neste período. Concluir o raciocínio enfatizando que, assim como todos nós, a Terra, e a própria vida, já esteve diferente em tempos passados (fazer a correlação com o calendário produzido).

Dessa forma, pode-se então iniciar os exemplos dos diferentes metabolismos em cachorros de porte diferentes, (que, aparentemente eles vivem tempos diferentes), concluindo por fim, que, apesar disso, eles devem ter a percepção do tempo de suas vidas de modo muito semelhante. Aqui há a possibilidade de se aprofundar (caso haja tempo suficiente) nas comparações entre mamíferos de tamanhos diferentes (como o rato e a baleia), mostrando um gráfico das diferenças de tamanhos desses organismos.

Ao tocar a música com sons produzidos pelas baleias pode-se perguntar se alguém reconhece o canto; informar que é de uma baleia; informar e

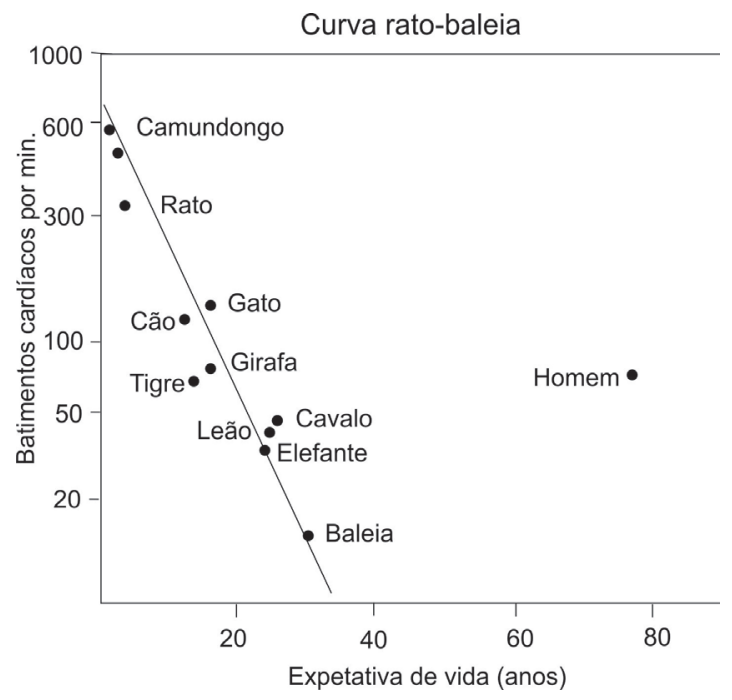

Gráfico 1 Curva "rato-baleia", uma comparação entre a longevidade e a taxa de batimento cardíaco em mamíferos. Retirado de Quora, 2016. discutir que a baleia é um mamífero; informar e discutir que após muitos estudos das gravações destes cetáceos encontrou-se um padrão que se repete a cada 30 minutos de canto, exatamente igual ao primeiro. Discutir se (nós, humanos) seríamos capazes de repetir este feito (cantar por 30 minutos sem parar para respirar, cantar padrões tão longos que se repetiriam somente de meia em meia hora).

Passar então para a aplicação dos tempos de vida e metamorfose de dois grupos distintos de organismos, com o objetivo de ilustrar a dificuldade de pensar sobre a relação tempo de vida e o evento geológico. Afinal, o tempo de vida de um organismo é, em geral, curto para perceber eventos geológicos importantes. Com base na comparação elaborada por Chambers, ora citada, escolhemos como exemplos dois organismos em estágios de vida diferentes, e o professor irá conduzir a turma para imaginar as situações a seguir com base nas informações biológicas das duas espécies animais: as pupas da borboleta Caligo martia e os girinos da rã-touro Rana catesbeiana. O professor pode iniciar a explicação tecendo comentários sobre o ciclo completo de ambas espécies que pode ser encontrado nos artigos de Casagrande e Mielke (2000), Bambozzi et al. (2004) e Specht e Paluch (2009). Dando destaque que as pupas de C. martia completam a metamorfose em 30 dias e, então, tem o início da fase adulta como imago, na forma de borboleta; enquanto que a metamorfose dos girinos de $R$. catesbeiana pode durar até três meses, dependendo das condições ambientais. Após esta breve introdução o professor pode construir o raciocínio de que pela diferença no tempo passado em cada fase do ciclo de vida destes organismos, certamente estes não perceberiam a presença um do outro. Portanto, na imaginação assumiremos que a borboleta teria tal consciência, e devido ao tempo curto de vida desta, perderia o vislumbre da transformação do girino da rã touro para a sua forma adulta. Como consequência a borboleta, agora emergida, conheceria o companheiro apenas como um girino, e levaria a termo o seu ciclo de vida sem o conhecer como uma rã. Ao final desta explanação aplicar a comparação realizada no texto de Chambers (transcrito anteriormente).

O exercício do tempo profundo deve então ser finalizado com a comparação borboleta $\mathrm{x}$ rã versus homem x história da Terra, demonstrando que o homem surgiu muito tarde na história da vida na Terra; abrir a discussão para ouvir os alunos em relação a essa percepção. 


\section{Considerações Finais}

Os três exemplos desenvolvidos neste texto refletem um contexto interdisciplinar que pode ser abordado em aulas de Biologia para o EM. Da mesma maneira, informam sobre contextos paleoambientais e questões centrais na evolução dos organismos e de nosso planeta, fornecendo uma visão ampla de assuntos que normalmente são vistos em sala de aula de maneira compartimentada. Espera-se que tais exemplos sejam úteis aos profissionais do EM, fornecendo ideias e modos de agir diferentes daqueles utilizados no cotidiano das escolas.

\section{Referências}

Anelli L.E., Simões M.G. 2011. Uma breve história do tempo. In: Paleoari Lucia M., Campos, R.S.P., Otsuka, H., Carvalho, M.B. eds. 2011. Experimentando ciência. Teorias e práticas para o ensino de biologia. São Paulo, Ed. UNESP. p. 23-49.

Bambozzi A.C., Filho J.T.S., Thomaz L.A., Oshiro L.M.Y. 2004. Efeito do fotoperíodo sobre o desenvolvimento de girinos de rã-touro (Rana catesbeiana Shaw, 1802). Rev. Bras. Zootecnia, 33(1):1-7.

Brasil. Secretaria da Educação Fundamental. 1998. Parâmetros Curriculares Nacionais: Ciências da Natureza, Matemática e outras tecnologias: Ensino Médio. Brasília, MEC/SEF, 58 p.

Brusca R.C. \& Brusca G.J. 2007. Invertebrados. 2 ed. Rio de Janeiro, Guanabara Koogan. 968p.

Carneiro C.D.R., Mizusaki A.M.P., Almeida F.F.M.de. 2005. A determinação da idade das rochas. Terre Didatica, 1(1):6-35.

Casagrande M.M., Mielke O.H.H. 2000. Larva de quinto estádio e pupa de Caligo martia (Godart) (Lepidoptera, Nymphalidae, Brassolinae). Rev. Bras. Zool., 17(1):75-79.

Choi C.Q. 2013. Why small pups outlive large dog breeds. Live Science Contributor, URL $<$ http://www.livescience.com/27676-why-small-pups-outlive-large-dogs.html> Acesso em: 11.02.2016

Duve C. 1997. Poeira Vital: a vida como imperativo cósmico. Rio de Janeiro, Ed. Campus. 471p.

Enciclopédia Britânica online URL < www.britannica.com/science > Acesso em11/02/2016.

Faria A.C.R., Crislei G., Santiago G., Silva K.S., Costa R.H., Rover D.M., Bernardes R. 2012. Ensino de Paleontologia em escolas públicas de ensino médio do Município de Divinópolis, MG. Rev. Professores em Formação, 3:1-7.

Fairchild T.R. 2003. A Terra: passado, presente e futuro. In: Teixeira, W., Toledo, M.C.M. Fairchild, T.R., Taioli, F. eds. Decifrando a Terra. São Paulo, Oficina de Textos, p. 494-516.
Filho, C.A.L. s/a Departamento Nacional de Produção Mineral. Superintendência em Pernambuco. In: Geologia e Mineração, Escala Geológica do Tempo. URL < http://www.dnpm-pe.gov.br/Geologia/ Escala_de_Tempo.php >. Acesso 11.02.2016.

Galis F., Sluijs I.V.D., Dooren T.J.M.V., Metz J.A.J., Nussbaumer M. 2007. Do large dogs die Young? J. Exper. Zool.(Mol. Dev. Evol.). 308B:119-126.

Gould S.J. 2004. O tempo de vida que nos foi concedido. In: O Polegar do Panda: Reflexões sobre história natural. São Paulo, Martins Fontes. 297 p.

Holz M., Ros L.F. 2000. Paleontologia do Rio Grande do Sul. CIGO/UFRGS, Porto Alegre, 397 p.

Hickman, C.P.Jr., Roberts, L.S., Keen, S.L., Eisenhour, D.J., Larson, A., Anson, H. 2013. Princípios Integrados de Zoologia. 15a Edição. Guanabara Koogan, Rio de Janeiro, RJ, 1951p.

Hill R.W., Wyse G.A., Anderson M. 2012. Fisiologia Animal. 2 ed. Porto Alegre, Artmed Ed. 894 p.

Margulis L., Sagan D. 2002. O que é Vida? Rio de Janeiro, Jorge Zahar Ed. 289p.

Moraes, S.S., Santos, J.F.S., Brito M.M.M. 2007. Importância dada à paleontologia na educação brasileira: uma análise dos PCN e dos livros didáticos utilizados nos colégios públicos de Salvador, Bahia. In: Paleontologia: Cenários da vida. Carvalho, I.S., Cassab, R.C.T., Schwanke, C., Carvalho, M.A., Fernandes, A.C.S., Rodrigues, M.A.C., Carvalho, M.S.S., Arai, M., Oliveira, M.E.Q. Rio de Janeiro, Editora Interciência, 652 p.

Pereira I.M.R, Filho A.A.B., Alvares B.R., Palomari E.T., Nanni L. 2008. Radiological determination of cranial size and index by measurement of skull diameters in a population of children in Brazil. Radiologia Brasileira, 41:4.

Quora URL. s.d. Why do smaller mammals have a shorter lifespan than larger mammals. < https://www. quora.com/Why-do-smaller-mammals-have-a-shorter-lifespan-than-larger-mammals > Acesso 11.02 .2016$.

Soares M.B. 2009. Livro Digital de Paleontologia: a paleontologia na sala de aula. Porto Alegre, Soc. Bras. Paleontologia.

Schmidt-Nielsen K. 1996. Fisiologia Animal. Adaptação e Meio Ambiente. Cambridge Univ. Press. São Paulo, Livraria Santos Ed. 600p.

Schwanke C., Silva M.A.J. 2004. Educação e Paleontologia. In: Carvalho, I.S. ed. Paleontologia. Rio de Janeiro, Ed. Interciência. vol.2, p. 123-130.

Schiel, D. 2009. Experimentoteca do Ensino Médio. URL: <http://www.cdcc.usp.br/exper/medio/>. Acesso 30.06.2013.

Specht M.J.S, Paluch M. 2009. Estágios Imaturos de Caligo illioneus illioneus (Cramer) (Nymphalidae: Morphinae: Brassolini). Neotropical Entomology, 38(6):801-808.

Suguio K., Suzuki U. 2003. A evolução geológica da Terra 
e a fragilidade da vida. São Paulo: Ed. Blücher. 152 p. Tyson N.G., Goldsmith D. 2015. Origens. Catorze bilhões de anos de evolução cósmica. São Paulo: Planeta do Brasil. 384p.

Resumo: Este artigo visa apresentar três exemplos de aplicação de temas paleobiológicos aplicáveis a salas de aulas do Ensino Médio (EM), conforme as sugestões de interdisciplinaridade de conteúdo em Biologia encontradas nos parâmetros curriculares nacionais (PCNEM). 0 principal objetivo é fornecer, a professores do EM, exemplos de conceitos que não estão facilmente acessíveis a eles na bibliografia destes anos iniciais. 0 uso destes conceitos em aula visa não somente formar alunos com conhecimentos práticos e contextualizados (para a vida profissional), mas também conhecimentos mais amplos e abstratos, com 0 intuito de que adquiram uma visão cultural ampla e construam sua visão de mundo (formaç̧ão do cidadão). Os conteúdos abordados são as mudanças ecológicas ocorridas no Éon Proterozoico, resultantes da atividade biótica, a evolução das ciências e 0 tempo profundo. Cada conceito é dividido em três partes: contextualização e aplicação, detalhamento da abordagem e atividade. Na contextualização o embasamento teórico e 0 referencial bibliográfico do assunto são fornecidos. No detalhamento sugerem-se as formas de abordagem do conteúdo em sala de aula, a união a conceitos de áreas externas à Biologia e os materiais necessários à aplicação da atividade. Por fim, há a explanação da atividade em si. Os três conceitos (mudanças ambientais passadas, desenvolvimento da ciência e tempo profundo) não se referem somente à Paleontologia, mas ao próprio desenvolvimento das Ciências em geral. Envolvem também contextos paleoambientais e questões centrais na evolução dos organismos e de nosso planeta, fornecendo uma visão ampla de assuntos que normalmente são vistos em sala de aula de maneira compartimentalizada. Tais exemplos em aula devem ser abordados de maneira interdisciplinar, devendo, sempre que possível, contar com a participação de mais de um professor.

Palavras-chave: tempo profundo, ciências, ecologia. 